\title{
Infection of CD8+CD45RO+ Memory T-Cells by HIV-1 and Their Prolif- erative Response
}

\author{
Naveed Gulzar ${ }^{1,2}$, Sowyma Balasubramanian ${ }^{3}$, Greg Harris ${ }^{2,3}$, Jaime Sanchez-Dardon ${ }^{3}$ and \\ Karen F.T. Copeland ${ }^{*}, 1$ \\ ${ }^{I}$ National HIV and Retrovirology Laboratories, Public Health Agency of Canada, Ottawa, Canada \\ ${ }^{2}$ Department of Biochemistry, Microbiology and Immunology, University of Ottawa, Ottawa, Canada \\ ${ }^{3}$ Ottawa Health Research Institute, Ottawa, Canada
}

\begin{abstract}
CD8+ T-cells are involved in controlling HIV-1 infection by eliminating infected cells and secreting soluble factors that inhibit viral replication. To investigate the mechanism and significance of infection of CD8+ T-cells by HIV-1 in vitro, we examined the susceptibility of these cells and their subsets to infection. CD8+ T-cells supported greater levels of replication with T-cell tropic strains of HIV-1, though viral production was lower than that observed in CD4+ T-cells. CD8+ T-cell infection was found to be productive through ELISA, RT-PCR and flow cytometric analyses. In addition, the CD8+CD45RO+ memory T-cell population supported higher levels of HIV-1 replication than CD8+CD45RA+ naïve Tcells. However, infection of CD8+CD45RO+ T-cells did not affect their proliferative response to the majority of mitogens tested. We conclude, with numerous lines of evidence detecting and measuring infection of CD8+ T-cells and their subsets, that this cellular target and potential reservoir may be central to HIV-1 pathogenesis.
\end{abstract}

Keywords: CD8+ T-Cell, HIV-1, memory, proliferation, subset.

\section{INTRODUCTION}

The Human Immunodeficiency Virus (HIV)/Acquired Immune Deficiency Syndrome (AIDS) pandemic is of great concern to the global population and much effort and research is necessary to understand and treat the viral disease. Currently, there are over 40 million people worldwide living with HIV/AIDS. HIV-1 is the etiologic agent that is responsible for AIDS, which occurs during the latter stages of viral pathogenesis (approximately 8-10 years after the initial infection).

A recent source of controversy exists over the nature of HIV-1 infection of CD8+ T-cells. CD8+ T-cells play a crucial role in the cell-mediated response of the immune system as these cells are able to recognize and eliminate cells infected with foreign pathogens through their Cytotoxic Tlymphocyte (CTL) abilities [1]. In addition to their CTL abilities, the CD8+ T-cell Non-cytotoxic Antiviral Response (CNAR) can produce and secrete a number of soluble HIV-1 inhibitory factors that can block intracellular viral replication in CD4+ T-cells and other cellular subsets [2]. While there is an early increase in the number and function of HIV-1 specific CTLs, it has been established that in chronic infection, the decline in the CD8+ T-cell response accompanies progression to symptomatic disease [3,4]. The significance and importance of CD8+ T-cells in viraemic control was elucidated in studies with Long-Term Non-Progressors (LTNP).

*Address correspondence to this author at the National HIV and Retrovirology Laboratories, Public Health Agency of Canada, 200 Tunney's Pasture Driveway Ottawa, Ontario, Canada K1A 0K9; Tel: 613-946-0365; Fax: 613-948-4026; E-mail: Karen_Copeland@phac-aspc.gc.ca
CD8+ T-cells from LTNPs of HIV-1 infection maintain normal CD8+ T-cell numbers, greater functionality and persistent HIV-1 specific CTL responses than those of progressors $[4,5]$.

Although the central focus of HIV-1 pathogenesis has been on the role of $\mathrm{CD} 4+\mathrm{T}$-cells, there has been much recent evidence demonstrating the susceptibility of CD8+ Tcells to HIV-1 infection both in vivo and in vitro (reviewed in [1]). The cause of CD8+ T-cell dysfunction and depletion during HIV-1 infection in vivo still remains unclear. This phenomenon is generally attributed to the lack of CD4+ Tcell help or to the secretion of soluble viral proteins in the viral milieu. It has been demonstrated that the presence of $\mathrm{CD} 4+\mathrm{T}$-cells and antigen presenting cells are critical in CD8+ T-cell maturation and function [6]. In addition, antigenic stimulation of CD8+ T-cells may result in a state of anergy and possibly cell death [7] inducing an accompaniment of chronic unresponsiveness in the immune system. Work done by Potter et al. and others have implicated CD8+ T-cells as a reservoir of circulating HIV-1 infected cells [8, 9]. Direct infection of CD8+ T-cells may also explain the abnormalities and dysfunction seen in this subset during AIDS pathogenesis. Over the past couple of years, numerous mechanisms have been proposed to explain HIV-1 entry into CD8+ T-cells. One such mechanism involved the selection of CD8-tropic variants of HIV-1 that were syncytium inducing and cytopathic for CD8+ T-cells [10, 11]. A few of these viral isolates from HIV-1 infected individuals were shown to be able to use the CD8 cell-surface molecule as a receptor [11]. Cell-to-cell transfer of viral particles has also been postulated as a mode of HIV-1 spread and entry into CD8+ T- 
cells $[12,13]$. Lastly, a number of investigators have shown that the expression of the CD4 molecule on CD8+ T-cells increased subsequent to activation [14-18]. These aptly termed $\mathrm{CD} 4{ }^{\text {dim }} \mathrm{CD} 88^{\text {bright }} \mathrm{T}$-cells were found to be susceptible to HIV-1 infection. Key studies by Hughes et al. demonstrated that virus derived from HIV-1 infected CD8+ T-cells accounted for approximately $15 \%$ of the plasma viral load in vivo [19].

One of the hallmarks of the immune system is the ability to generate memory. This defining aspect of the immune response is critical in controlling and recognizing viral infections. In response to an infection, CD8+ T-cells differentiate. Upon antigen recognition through Major Histocompatibility Complex (MHC)-I molecules, naïve CD8+ T-cells (CD8+ $\mathrm{CD} 45 \mathrm{RA}+\mathrm{CD} 28+\mathrm{CCR} 7+$ ) become activated and differentiate into memory $(\mathrm{CD} 8+\mathrm{CD} 45 \mathrm{RO}+\mathrm{CD} 28+\mathrm{CD} 27+\mathrm{CCR} 7+)$ and effector (CD8+CD45RA+CD28-CD27-CCR7-) T-cells [20]. Once the immune response subsides and the infection is cleared, the majority of the activated CD8+ T-cells are eliminated, but a few remain circulating in the immune system. These circulating cells exist as memory cells that are pathogen-specific [21]. In addition, the memory $\mathrm{CD} 8+\mathrm{T}$ cells are able to circulate for extended periods of time because of high levels of anti-apoptotic molecules [22] and, unlike naïve $\mathrm{CD} 8+\mathrm{T}$-cells, they are able to proliferate in the absence of antigen in vivo [23].

Impairment of the function and activities of CD8+ Tcells could allow the virus to escape from immune containment and further contribute to the deterioration of the infected individual's health. Early studies examining the effects of HIV-1 infection of CD8+ T-cells noted that infection was minimal in vivo. However, these studies did not use very sensitive techniques to detect HIV-1 infection and the associated effects. More recent studies using sensitive quantitative RT-PCR and flow cytometry have demonstrated frequent infection of CD8+ T-cells. To investigate the susceptibility of CD8+ T-cells to HIV-1 infection in vitro and the functional significance of infection, we examined levels of HIV-1 replication and the effects of viral infection in CD8+ $\mathrm{T}$-cells and T-cell subsets. The susceptibility of CD8+ Tcells to T-cell tropic and macrophage tropic strains of HIV-1 was also analyzed. In addition, we determined the frequency of HIV-1 infection in the CD8+ T-cell population as measured by an intracellular HIV-1 assay. Lastly, we examined the effects of HIV-1 infection on CD8+ T-cell subsets. We hypothesized that CD8+ T-cells would be able to support productive HIV-1 replication and may serve a role as a cellular reservoir for HIV-1 production and replication. From our results, we observed that $\mathrm{CD} 8+\mathrm{T}$-cells were able to support productive infection with $\mathrm{T}$-cell tropic viral strains independent of CD4 cell-surface expression. Interestingly, HIV-1 replicated preferentially in the CD8+ T-cell memory subset, resulting in an increase in the activation state of these cells. However, the infection-induced activation did not alter the ability of the memory T-cells to proliferate in response to the majority of mitogens used for stimulation. The identification of a potential novel cellular target and reservoir may have a profound effect on our views of HIV-1 disease progression and treatment.

\section{MATERIALS AND METHODOLOGY}

\section{Isolation of Lymphocyte Populations}

Blood samples from healthy volunteers were collected into tubes containing Ethylenediamine Tetra-acetic Acid (EDTA) by venipuncture. Samples were diluted with an equal volume of Phosphate Buffered Saline (PBS) and Peripheral Blood Mononuclear Cells (PBMCs) were isolated by Ficoll-Hypaque (Amersham Biosciences, Baie d'Urfe, $P Q)$ density centrifugation. Subsequent to density centrifugation, isolated PBMCs were washed twice in PBS. CD8+ and CD4+ T-cell populations were isolated from freshly purified PBMCs through positive selection using anti-CD8 and -CD4 conjugated magnetic beads (Miltenyi, Auburn, CA) respectively, according to the manufacturer's protocol. Briefly, cells were labeled with the magnetically conjugated antibody of interest for 20 minutes at $4^{\circ} \mathrm{C}$. Subsequent to labeling, cells were placed through a column inserted in the magnetic field of a MACS separator (Miltenyi) and unbound cells were washed with MACS buffer (PBS, 0.5\% Bovine Serum Albumin (BSA), 2 mM EDTA, pH 7.2). After washing unbound cells, the column was removed from the separator and the labeled cells were eluted with the addition of MACS buffer. Following elution, the isolated T-cell subsets were washed twice with PBS.

The isolation of CD8+ T-cell subsets was performed using anti-CD8 Multisort conjugated magnetic beads (Miltenyi). In order to isolate the T-cell subsets, a second round of positive selection with magnetic bead-conjugated antibodies to either CD45RO+ or CD45RA+ was performed. Similarly, CD28, CD38 and HLA-DR positive and negative populations were selected using the Multisort conjugated magnetic beads.

\section{Cell Culture}

PBMCs and T-cell subsets were cultured in RPMI-10 (RPMI 1640 medium supplemented with $10 \%$ Fetal Calf Serum (FCS), $100 \mathrm{U} / \mathrm{mL}$ penicillin (Invitrogen, Burlington, $\mathrm{ON}$ ), $100 \mu \mathrm{g} / \mathrm{mL}$ streptomycin (Invitrogen), and $20 \mathrm{U} / \mathrm{mL}$ Interleukin (IL)-2 (Sigma-Aldrich, St. Louis, MO)). Cells were incubated at $37^{\circ} \mathrm{C}$ with $5 \% \mathrm{CO}_{2}$.

\section{Sources of Viruses}

The T-cell tropic laboratory strain $\mathrm{HIV}_{\text {IIIB }}$ was obtained from Advanced Biotechnologies Incorporated (Columbia, $\mathrm{MD})$. The macrophage tropic laboratory strain, $\mathrm{HIV}_{\mathrm{ADA}}$, was obtained from the National Institutes of Health (NIH) AIDS Research and Reference Reagent Program (Germantown, MD). The clinical isolates of HIV-1 were generated from the blood of HIV-1 infected individuals. Briefly, PBMCs were isolated from the peripheral blood of infected subjects by Ficoll-Hypaque density centrifugation. The CD8+ T-cell fraction was removed from the isolated PBMCs through the use of anti-CD8 conjugated magnetic microbeads. The remaining cells were subsequently cultured with HIV-negative PHA blastocytes in RPMI-10. The cultures were monitored at days 10 and 15 for HIV-1 p24 production by an EnzymeLinked Immunosorbent Assay (ELISA) (SAIC-Frederick Inc., Frederick, MD). 
The titre of the viral stock was determined by a $\mathrm{TCID}_{50}$ assay. Briefly, $100 \mu \mathrm{L}$ serial dilutions of the viral stock (approximately $1,500 \mathrm{ng} / \mathrm{mL}$ as determined by a HIV-1 p24 ELISA) was used to infect 250,000 MT2 cells (American Type Culture Collection (ATCC), Manassas, VA) in quadruplicate in a 96-well flat bottom plate. Subsequent monitoring for the formation of syncytia was performed over a 7-day culture period. The titre of the viral stock was determined by the Reed-Muench accumulative method. The titre of the $\mathrm{HIV}_{\text {IIIB }}$ viral stock used for CD8+ T-cell infections was found to be $1 \times 10^{5}$. Unless otherwise noted, $300 \mathrm{TCID}_{50} / \mathrm{mL}$ of the viral inoculum for each of the viral isolates was used to infect isolated cells at a density of $1 \times 10^{6}$ cells $/ \mathrm{mL}$ during the course of the in vitro experiments.

\section{HIV-1 Infection and Monitoring of Replication in CD8+ T-Cell Populations}

Immediately after isolation and prior to infection, CD8+ T-cells were stimulated with $2.5 \mu \mathrm{g} / \mathrm{mL}$ of Phytohemagglutinin (PHA) (Sigma-Aldrich) for three hours followed by subsequent washes and a 1 hour incubation with $2 \mu \mathrm{g} / \mathrm{mL}$ polybrene (Sigma-Aldrich) in RPMI-10. Subsequently, the cells were washed, re-cultured in RPMI-10 and infected with 300 $\mathrm{TCID}_{50} / \mathrm{mL}$ of the appropriate viral strains and isolates. Three days after the infection, the cells were extensively washed to remove any extracellular virus and debris and were re-cultured in RPMI-10 and this time point was considered the zero time point in the infection assays. In order to determine the levels of HIV-1 replication and production, cell-free supernatants were taken at days 5, 10 and 15 (or as indicated in the results and figures) post-infection from the infected cell cultures. Virus replication was assessed by HIV-1 production as measured by an ELISA (SAICFrederick Inc.). In order to normalize our results, supernatants were taken from cultures of CD8+ T-cells derived from several different individuals.

In order to assess productive infection, the reverse transcriptase inhibitor, Azidothymidine (AZT) (NIH AIDS Research and Reference Reagent Program) was used to treat the cells at a concentration of $10 \mu \mathrm{M}$ for one hour prior to infection and was not used further throughout the time course.

\section{Nucleic Acid Extraction and Detection of Productive HIV-1 Infection by RT-PCR Analysis}

Total RNA was isolated from $3 \times 10^{6}$ cells using the GeneElute Mammalian Total RNA Miniprep Kit (SigmaAldrich). First strand cDNA was reverse transcribed with a $\operatorname{pd}(\mathrm{N})_{6}$ primer and Moloney Murine Leukaemia Virus (MMLV) reverse transcriptase using the First-Strand cDNA synthesis kit (Amersham Biosciences) according to the manufacturer's protocol. RT-PCR reactions were set up for each cDNA towards the gag region of HIV-1 (p24 forward: 5'-ATAGAGGAAGAGCAAAACAAAA-3'; p24 reverse: 5'-CAAAATTACCCTATAGTGCA-3'). Each reaction was conducted in a total volume of $25 \mu \mathrm{L}$ containing $2.5 \mu \mathrm{L}$ of 2 $\mathrm{mM}$ dNTP (Amersham Biosciences), $1.25 \mu \mathrm{L}$ of $50 \mathrm{mM}$ $\mathrm{MgCl}_{2}$ (Amersham Biosciences), $1 \mu \mathrm{L}$ of each primer (from a $100 \mathrm{mM}$ stock) and $1 \mathrm{U}$ of Taq DNA polymerase (Amersham Biosciences). A total of $5 \mu \mathrm{L}$ of each cDNA was used in the RT-PCR analysis. RT-PCR amplification was performed for 35 cycles of: denaturing at $94^{\circ} \mathrm{C}$ for 60 seconds, annealing at $55^{\circ} \mathrm{C}$ for 60 seconds and extension at $72^{\circ} \mathrm{C}$ for 60 seconds. This was followed by a final extension for 10 minutes at $72^{\circ} \mathrm{C}$. RT-PCR amplicons were run at $80 \mathrm{~V}$ on a $1 \%$ agarose gel containing $0.5 \mu \mathrm{g} / \mathrm{mL}$ of ethidium bromide and visualized under Ultraviolet (UV) light.

\section{Flow Cytometric Analysis}

Flow cytometric analysis was gated on the live cell populations. Measurement of the levels of intracellular HIV-1 staining was performed as follows: $1 \times 10^{6}$ cells were permeabilized with the Fix \& Perm cell permeabilization kit (Caltag Laboratories, Burlingame, CA) according to the manufacturer's protocol. Cells were labeled with $10 \mu \mathrm{L}$ of the appropriate fluorochrome-conjugated monoclonal antibodies CD8-PC5 (Serotec, Raleigh, NC), CD4-PC5 (Serotec) and

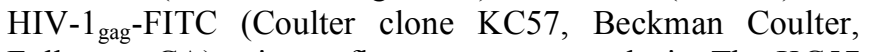
Fullerton, CA) prior to flow cytometry analysis. The KC57 antibody identifies HIV-1 core antigens (p55, p39, p33 and p24). Results were assessed on an Epics ALTRA system (Beckman Coulter) after gating on lymphocytes based on their forward and side scatter properties. Analysis was performed using Expo32 software (Applied Cytometry Systems, Sacramento, CA) and was based on a minimum of 10,000 events. Values are expressed as the mean fluorescence intensity.

For the analysis of the purity of the isolated populations of CD8+ T-cells, the following fluorochrome-conjugated monoclonal antibodies were used: CD8-PE (Serotec), CD4FITC (Serotec), CXCR4-PE (BD Biosciences, San Diego, CA), CCR5-PE (BD Biosciences), IgG-FITC (BD Biosciences), CD3-FITC (BD Biosciences), CD56/16-PE (BD Biosciences). For flow cytometric analysis, the cells of interest were washed twice in PBS and once in flow binding buffer (PBS, $0.1 \% \mathrm{NaN}_{3}, 2 \% \mathrm{BSA}$ ). The cells were subsequently resuspended at a concentration of $1 \times 10^{6}$ cells per $100 \mu \mathrm{L}$ of flow resuspension buffer and were labeled with 10 $\mu \mathrm{L}$ of the appropriate antibody for 30 minutes at room temperature. Prior to flow cytometric analysis, the cells were fixed in $200 \mu \mathrm{L}$ of $\mathrm{PBS} / 4 \%$ paraformaldehyde at $4^{\circ} \mathrm{C}$ for 5 minutes. Cell-surface molecule expression during the course of HIV-1 infection was examined in positively selected cells using CD8-PE (Serotec), CD4-FITC (Serotec), CXCR4-PE (BD Biosciences), CCR5-PE (BD Biosciences), CD45RAPE (BD Biosciences), CD45RO-FITC (Immunotech, Fullerton, CA), CD28-FITC (BD Biosciences), CD38-FITC (BD Biosciences) and HLA-DR-FITC (BD Biosciences) conjugated monoclonal antibodies. In order to determine the surface expression of both CD45RA and CD45RO in the CD8+CD4- and CD8+CD4+ populations, cells were examined by flow cytometry at day 5 post-infection after staining with antibodies directly conjugated to FITC.

\section{Lymphocyte Proliferation Assay}

Lymphocyte proliferation was measured by the XTT based colorimetric assay (Roche Laboratories, Meylan, France). In the memory CD8+ T-cell studies, $\mathrm{CD} 8+\mathrm{CD} 45 \mathrm{RO}+\mathrm{T}$-cells were positively isolated from the 
PBMCs of a healthy volunteer by magnetic labeling. Cells were either left uninfected or infected with $300 \mathrm{TCID}_{50} / \mathrm{mL}$

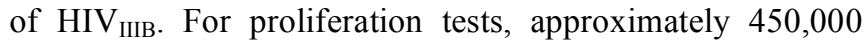
cells were seeded in triplicate in $100 \mu \mathrm{L}$ of culture medium (RPMI-10 supplemented with $20 \mathrm{U} / \mathrm{mL}$ of IL-2) per well of a 96-well flat bottom plate. Cells were incubated in the presence of each of the following mitogens: $3 \mu \mathrm{g} / \mathrm{mL}$ $\alpha C D 3 / C D 28$ (Sigma-Aldrich); $10 \mathrm{ng} / \mathrm{mL}$ Phorbol Myristate Acetate (PMA) (Sigma-Aldrich); $2 \mathrm{U} / \mathrm{mL}$ Tetanus Toxoid (TT) (Sigma-Aldrich); and $5 \mu \mathrm{g} / \mathrm{mL}$ PHA. On days 2-3 postmitogenic stimulation, cells were labeled with $50 \mu \mathrm{L}$ of the XTT labeling reagent as per the manufacturer's protocol. The proliferation index was assessed by measuring the absorbance at $492 \mathrm{~nm}$ (with a reference wavelength at $690 \mathrm{~nm}$ ) 18 hours post-labeling.

\section{Statistical Analysis}

Data are expressed as the mean \pm SEM. Differences in measured variables between experimental and control groups were assessed using the Student's $t$ test. Statistical significance was accepted at $p<0.05$.

\section{RESULTS}

\section{Susceptibility of Primary Blood-Derived CD8+ T-Cells to HIV-1 Infection In Vitro}

After establishing the purity of the selected CD8+ T-cell population and demonstrating the absence of any contaminating CD4+ T-cells or Natural Killer (NK) cells (data not shown), the ability of CD8+ T-cells to support HIV-1 infection was ascertained. In vitro infection of primary CD8+ Tcells was performed with $\mathrm{T}$-cell and macrophage tropic strains of HIV-1, along with Non-Syncytia Inducing (NSI) and Syncytia Inducing (SI) clinical isolates of the virus. The CD8+ T-cells were infected with an equal amount of virus, allowing the infection sensitivity of the CD8+ T-cells for the viral isolates and strains to be compared. Fig. (1A) shows a 15 day time course of virus replication of the two laboratory strains and the two clinical isolates of HIV-1 in positively selected CD8+ T-cells. As measured by a HIV-1 p24 ELISA, the T-cell tropic strain, $\mathrm{HIV}_{\mathrm{IIIB}}$, maintained the highest levels of viral production in the CD8+ T-cell population and the levels of virus replication for the HIV IIIB $_{\text {strain reached a }}$ peak at day 15 post-infection (Fig. 1A). The replication of the T-cell tropic clinical isolate was also supported in CD8+ T-cells, although to lower levels than the laboratory strain. Similarly, CD8 + T-cells also supported moderate levels of replication of the macrophage tropic laboratory strain, $\mathrm{HIV}_{\mathrm{ADA}}$, but replication of the macrophage tropic clinical isolate was poor.

In contrast to the viral kinetics of the T-cell and macrophage tropic laboratory strains and the T-cell tropic clinical isolate, the levels of HIV-1 production for the macrophage tropic clinical isolate declined over the 15 day time course. Input virus was not the cause of the low levels of viral production observed by this clinical isolate as CD8+ T-cells were extensively washed 3 days post-infection and day 0 of the infection assay was denoted at this point. Based on the above results, the $\mathrm{HIV}_{\text {IIIB }}$ strain was used in subsequent ex- periments due to the ability of CD8+ T-cells to support high levels of replication of this virus.

Most HIV-1 strains require CXCR4 or CCR5 as a coreceptor for viral entry, along with CD4 expression. The surface expression of the chemokine receptors on primary CD8+ T-cells was examined by flow cytometry. It was observed that the CXCR4 chemokine receptor was significantly expressed on the surface of the CD8+ T-cells $(55.9 \% \pm 2.1$, Fig. 1B). The expression of the CCR5 chemokine receptor was only moderately expressed on the CD8+ T-cell-surface $(11.6 \% \pm 1.0$, Fig. 1C). Comparison of viral replication kinetics was assessed between CD8+ and CD4+ T-cells over a 15 day time course (Fig. 1D). CD8+ T-cells were found to support approximately 10-fold lower levels of HIV-1 replication than CD4+ T-cells in vitro. Fig. (1D \& 1A) illustrate differences in $\mathrm{CD} 8+\mathrm{T}$-cell infection and replication kinetics of viral production. A caveat of in vitro infection is the observation of these variances due to differences in CD8+ Tcell populations used for the studies and the requirement for cell culture activation through cytokines/antigens for productive infection.

Productive infection was demonstrated by RT-PCR analysis. Only HIV-1 infected CD8+ and CD4+ T-cells, showed that viral infection was productive as both $\mathrm{T}$-cell populations showed a HIV-1 gag-specific band when RTPCR analysis was performed (Fig. 2A). Productive infection was also demonstrated in Fig. (2B) where the presence of AZT abrogated HIV-1 replication in CD8 + T-cells isolated from two volunteers. Differences in the levels of viral production were also observed between the two subjects. Subject 2 supported lower levels of HIV-1 production in their isolated CD8+ T-cells in the absence of AZT, indicating differences in viral replication supported by CD8+ T-cells from various individuals.

To further determine whether CD8+ T-cells could support HIV-1 infection, flow cytometry was performed to detect the presence of HIV-1 p24 (HIV-1 gag) intracellularly in this population. As shown in Fig. (3A, circle, upper right quadrant), $6.5 \%$ of the total $\mathrm{CD} 8+\mathrm{T}$-cell population were infected intracellularly with $\mathrm{HIV}-1_{\text {gag. }}$. As a control for the experiment, the contribution of CD8+CD4+ cells to the $6.5 \%$ of total infected cells was determined. The isolated and infected CD8+ T-cells were stained additionally with a CD4 antibody and intracellular HIV-1 expression was again measured by flow cytometry (Fig. 3B). From the results, approximately $1.6 \%$ of the $\mathrm{CD} 8+\mathrm{CD} 4+$ cells contributed to the total levels of the CD8+ T-cell infection obtained in Fig. (3A). They did not contribute significantly to the total levels of infection due to the low mean fluorescence intensity of this population. Two distinct populations of CD8+ T-cells were observed in the flow cytometric analysis based upon the expression levels of the CD8 molecule. These populations, that have been observed by others, differ in their surface expression of the CD8 cell-surface molecule and have been aptly termed $\mathrm{CD} 8^{\text {high }}$ and $\mathrm{CD} 8^{\text {low }}$ expressing populations $[24,25]$. A similar experiment illustrated that approximately $20-25 \%$ of CD4+ T-cells stained intracellularly for HIV-1 (data not shown). 
A

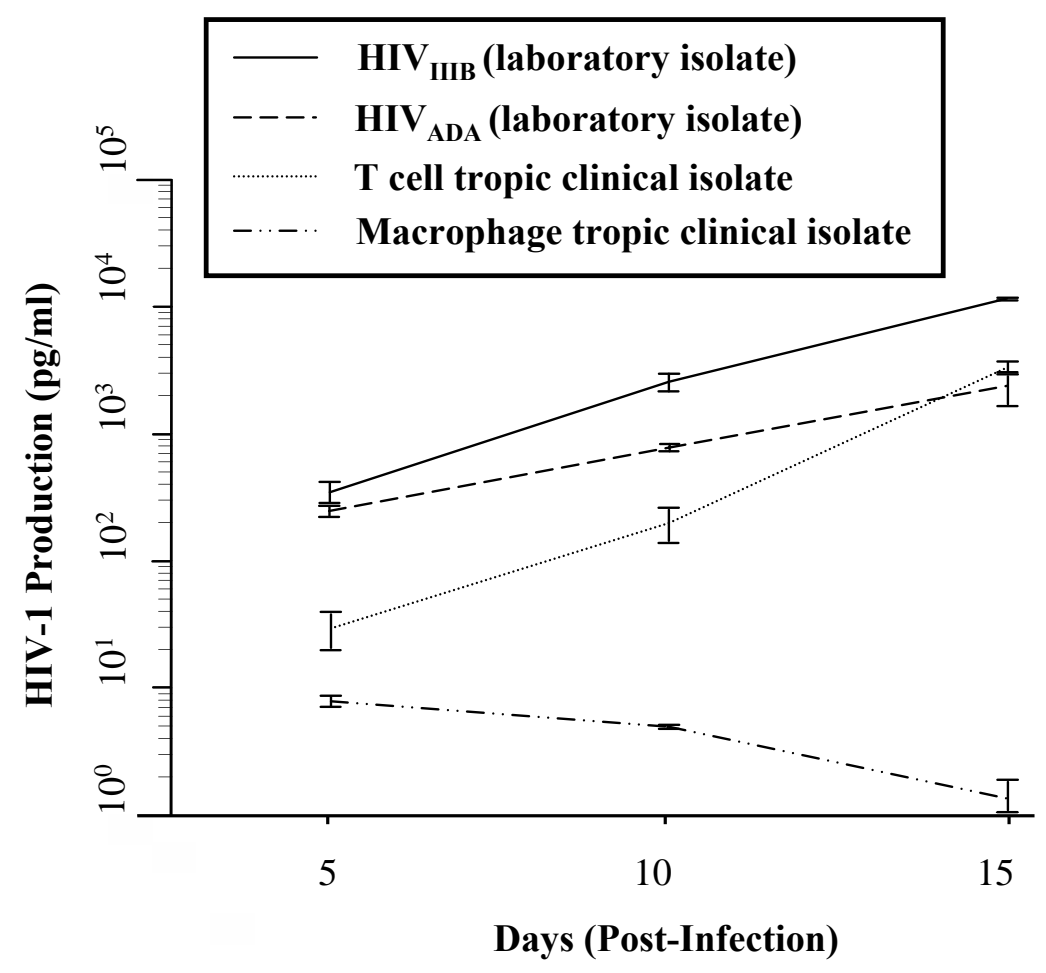

B

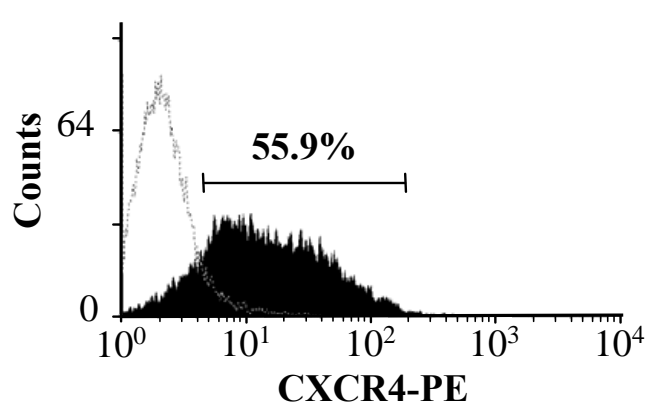

C

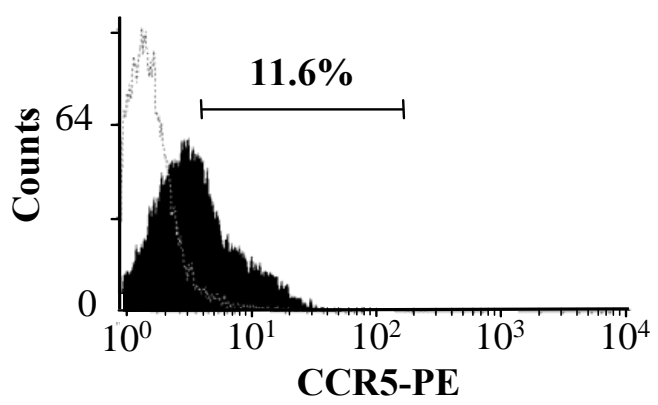

D

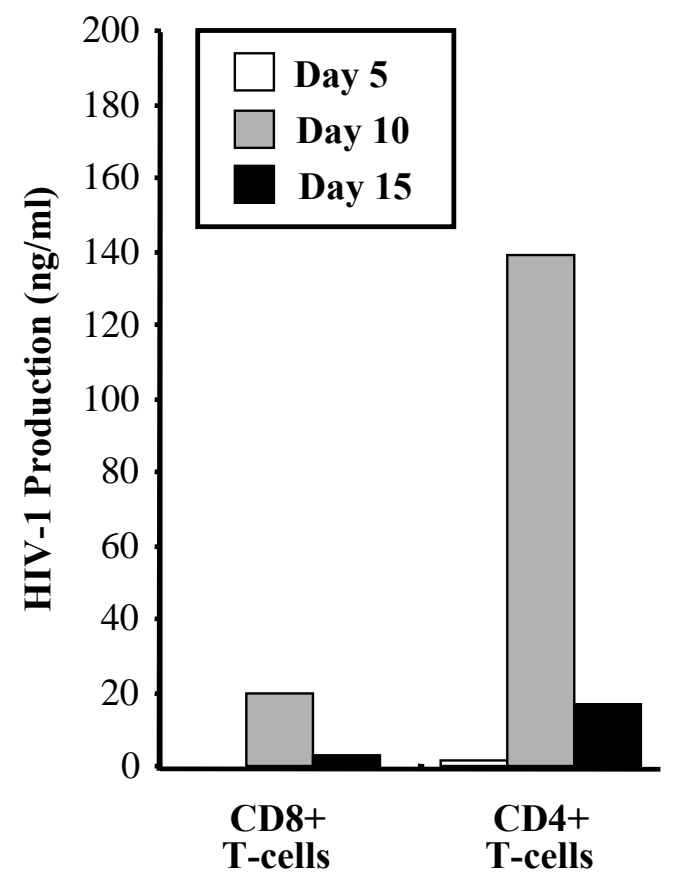

Fig. (1). Infection of CD8+ T-cells by HIV-1. (A) Selected CD8+ T-cells were infected with $300 \mathrm{TCID}_{50} / \mathrm{mL}$ of the T-cell tropic and macrophage tropic laboratory strains and clinical isolates of HIV-1. HIV-1 p24 production was measured by an ELISA at the indicated time points with cell-free supernatants from cultures. Results show the mean HIV-1 production and SEM of three independent experiments. (B) CXCR4 receptor expression on CD8+ T-cells as measured by flow cytometry. One representative of three experiments is shown. The mean fluorescence intensity of CXCR4 receptor and SEM of three independent experiments is $55.9 \% \pm 2.1$. (C) CCR5 receptor expression on CD8+ Tcells. One representative of three experiments is shown. The mean fluorescence intensity of CCR5 receptor and SEM of three independent experiments is $11.6 \pm 1.0$. CD8+ T-cells were also stained with negative controls (isotype control, dashed line). (D) Positively selected CD4+ and CD8+ T-cells were infected with $300 \mathrm{TCID}_{50} / \mathrm{mL}$ of $\mathrm{HIV}_{\mathrm{IIIB}}$. HIV-1 production was measured by an ELISA at the indicated time points from cell-free supernatants. 
A

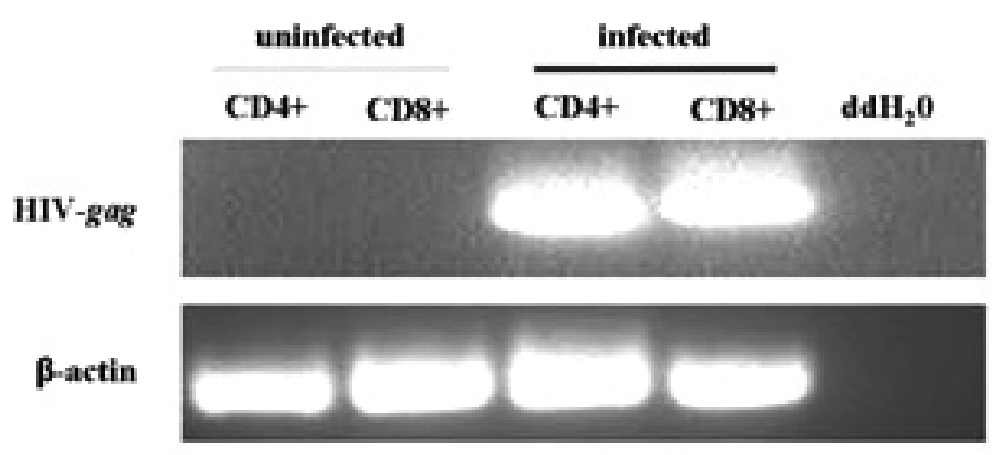

B

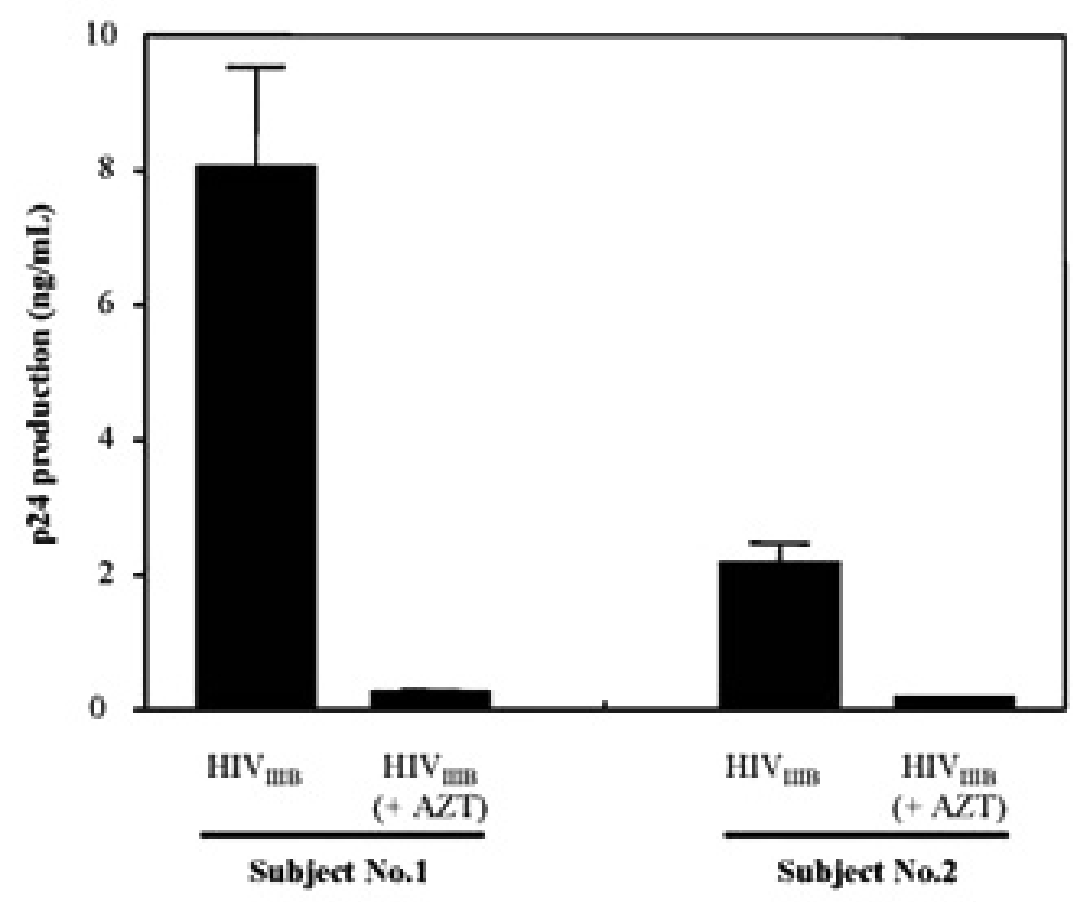

Fig. (2). Productive HIV-1 infection of CD8+ T-cells in vitro. (A) RT-PCR analysis of HIV-gag transcripts in the uninfected and infected populations of isolated CD4+ and CD8+ T-cells. Isolated lymphocyte populations were left uninfected or infected with $300 \mathrm{TCID} 50 / \mathrm{mL}$ of HIV $_{\text {IIIB }}$ for 7 days prior to RT-PCR analysis. Detection of $\beta$-actin was run as a loading control. Parallel samples were run without reverse transcriptase as a control for DNA contamination of the samples (data not shown). (B) Infection of CD8+ T-cells is sensitive to AZT. Infection was performed in the absence and presence of AZT and HIV-1 production was measured by an ELISA for the HIV-1 gag protein, p24. Cells were treated with $10 \mu \mathrm{M}$ of AZT for one hour prior to infection. CD8+ T-cells from two uninfected individuals were infected with 300 $\mathrm{TCID}_{50} / \mathrm{mL}$ of HIV $\mathrm{IIIB}$ laboratory strain. The results shown are the mean and SEM of three independent experiments.

Expression of the CD4 Cell-Surface Molecule on the Surface of CD8+ T-Cells During HIV-1 Infection

To examine the possibility of CD4 up-regulation in the in vitro infection system used throughout the studies, CD8+ Tcells were infected and monitored for CD4 expression by flow cytometry over a 12 day time course (Fig. 4). Interpretation of the flow cytometry data showed very distinct populations. Analysis of both the uninfected and infected CD8+ T-cell populations showed that CD4 expression on these cells reached a maximum of $0.4 \%$ and $0.5 \%$, respectively, on day 12 of culture. This suggests that cell culture conditions, not HIV-1 infection per se, resulted in this observed upregulation of $\mathrm{CD} 4$ on the surface of $\mathrm{CD} 8+\mathrm{T}$-cells. The overall majority of CD8+ T-cells were of the single-positive phenotype and the contribution of Double Positive (DP) cells was found to be minimal.

\section{Memory CD8+ T-Cells Support Higher Levels of HIV-1 Replication}

Subsets of CD8+ T-cells have been shown to be significant in the control of HIV-1 infection and disease progression. It has been postulated that higher levels of CD8+ 
A

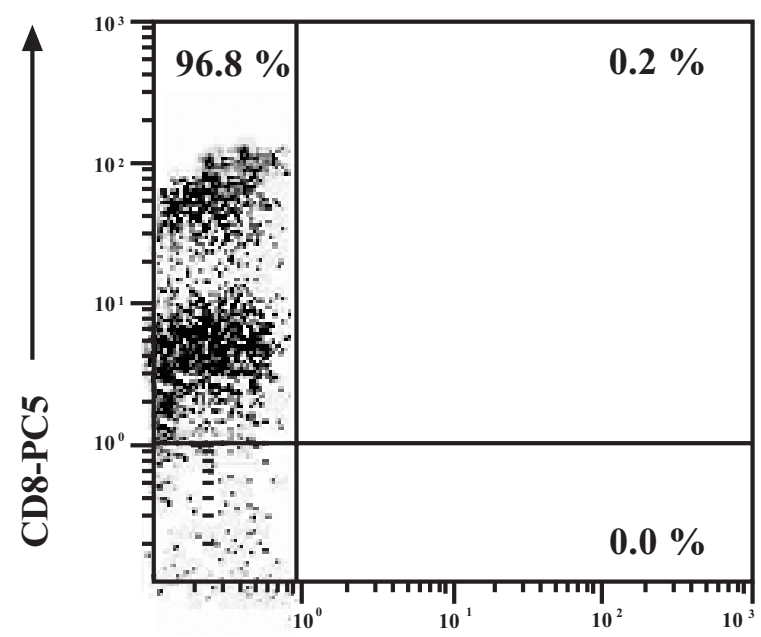

HIV-1 ${ }_{\mathrm{gag}}-\mathrm{RD} 1$
Infected

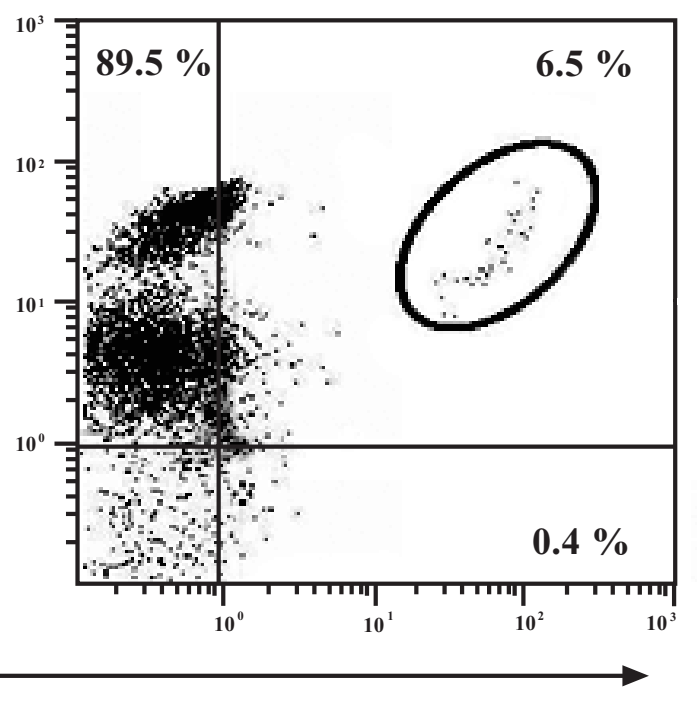

Infected

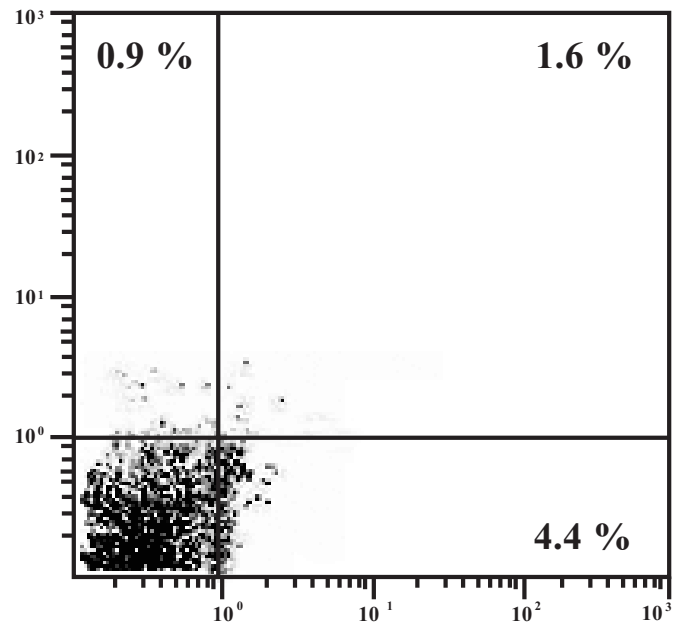

HIV-1 ${ }_{\text {gag }}$-RD1

Fig. (3). Detection of intracellular HIV-1 expression in CD8+ T-cells. CD8+ T-cells were infected with $300 \mathrm{TCID} 50 / \mathrm{mL}$ of $\mathrm{HIV}$ IIIB or left uninfected. (A) Intracellular p24 was examined on the CD8+ T-cell population by flow cytometry at day 15 post-infection with antibodies to HIV $-1_{\text {gag }}$ (p24-RD1) and CD8. In the infected population, the number in the upper right quadrant represents the number of cells found in the circle as to minimize any false-positives. (B) To determine the contribution of CD4+ cells to in vitro CD8+ T-cell infection, intracellular HIV-1 expression was examined in the CD8+ T-cell population by flow cytometry at day 15 post-infection with antibodies to HIV-1 $1_{\text {gag }}$ and CD4 only. Numbers in the quadrants represent the percentage of gated cells in each quadrant. A minimum of 10, 000 events was assessed for each analysis.

CD38+ T-cells may be associated with poor prognosis and were found to be elevated in individuals who have progressed to AIDS [26, 27]. In contrast, high levels of CD8+HLA-DR+ cells were observed in asymptomatic individuals [28]. In studies with CD8+ CTLs, HLA-DR expression was found to cor- relate with proliferation and CD28 expression [29]. Based on the possibility that HIV-1 infection may be involved in hindering the function and activities of various key CD8+ T-cell subsets, the susceptibility of the aforementioned subsets to in vitro HIV-1 infection was examined. Viral production was 
Day 3

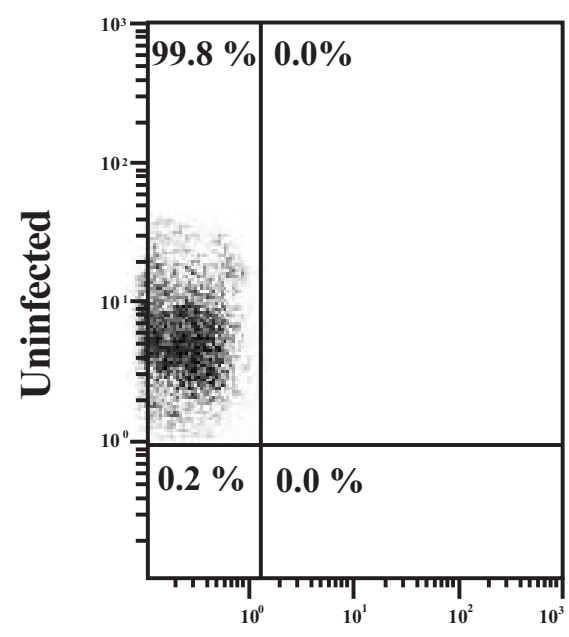

Day 9

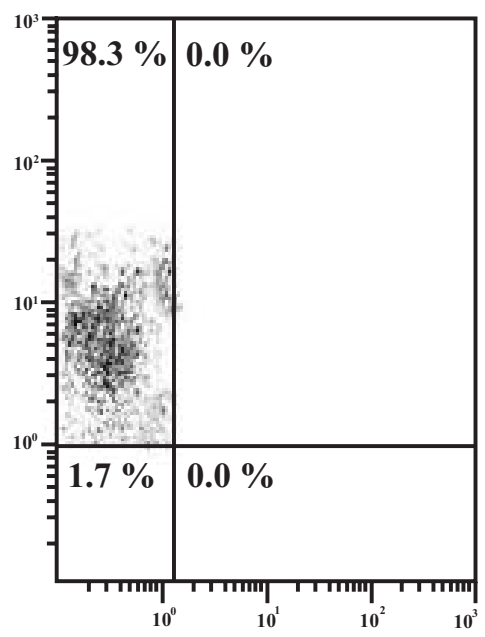

Day 12

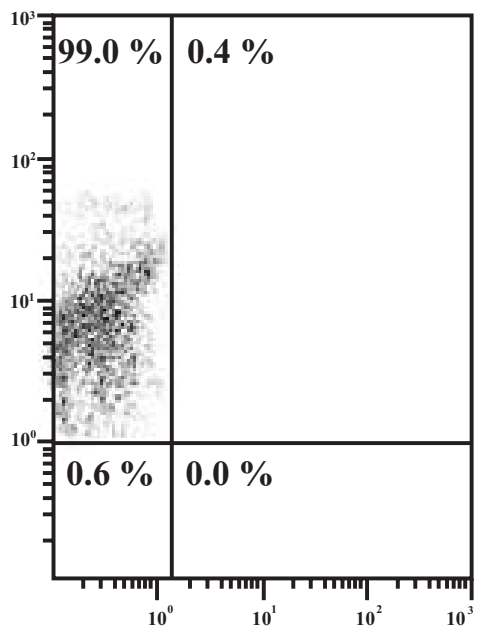

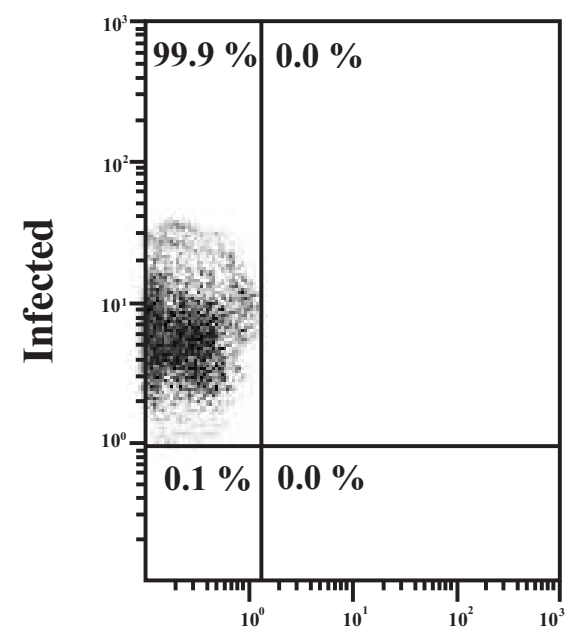
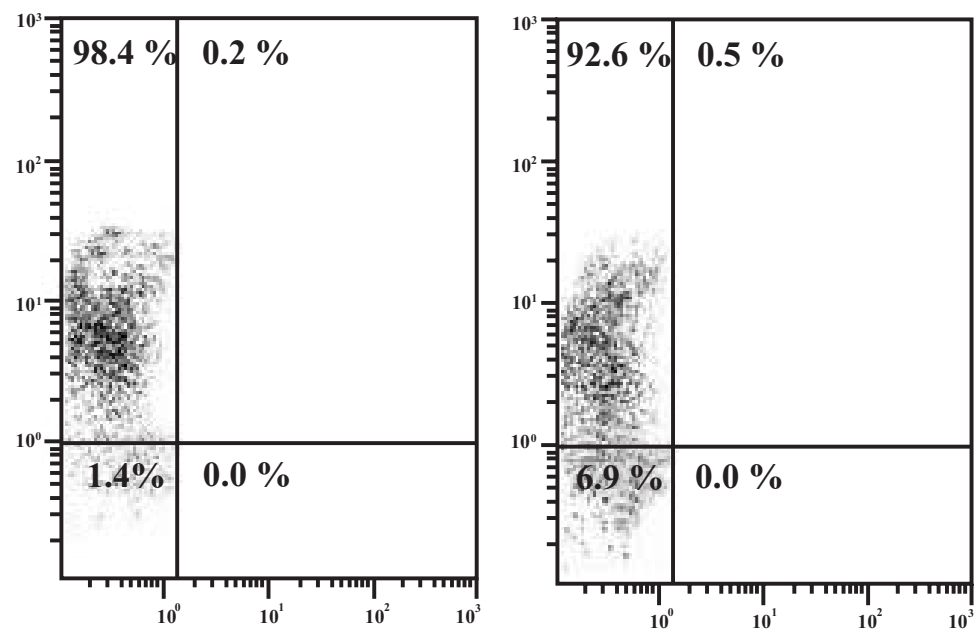

CD4-FITC

Fig. (4). CD4 cell-surface molecule up-regulation on the surface of CD8+ T-cells. Uninfected and HIV-1 infected CD8+ T-cells were examined at the indicated time points by flow cytometry for the expression of the CD8 and CD4 cell-surface molecules. CD8+ T-cells were infected with $300 \mathrm{TCID}_{50} / \mathrm{mL}$ of $\mathrm{HIV}_{\mathrm{IIIB}}$ and cell-surface expression of CD8 and CD4 was assessed at days 3, 9 and 12 by flow cytometry. Numbers in the quadrants represent the percentage of gated cells in each quadrant. A minimum of 10,000 events were assessed for each analysis.

measured in the CD8+ T-cell subset cultures over a 10 day time course by a HIV-1 p24 ELISA. The negative fractions obtained from the subset isolation were also assessed for HIV1 production. Interestingly, the $\mathrm{CD} 8+\mathrm{CD} 28+, \mathrm{CD} 8+\mathrm{CD} 38+$ and CD8+HLA-DR+ subsets all supported very low levels of HIV-1 replication (Fig. 5A). In fact, the levels of viral production decreased over the course of in vitro infection in these subsets. Fig. (5A) also showed that 2.5 - 4 fold higher levels of replication were supported in the CD8+CD28-, CD8+CD38and CD8+HLA-DR- populations, compared to the positive fractions.

Susceptibility of the memory and naïve CD8+ T-cell populations was also examined in response to HIV-1 infec-

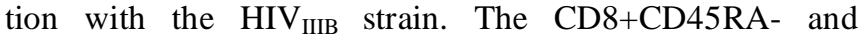
CD8+CD45RO+ memory cell populations both supported approximately $5-10$ times higher levels of HIV-1 replication than the CD8+CD45RA+ and CD8+CD45RO- naïve populations (Fig. 6A). The p24 levels obtained in these experiments were lower than the levels found in previous experiments, as these infections were performed using lower levels of PHA stimulation to minimize any possible upregulation of receptors. We examined receptor expression during the course of infection (Fig. 6B) and confirmed by flow cytometry that there was no alteration in receptor expression during the course of in vitro infection within the memory and naïve CD8+ T-cell populations. 


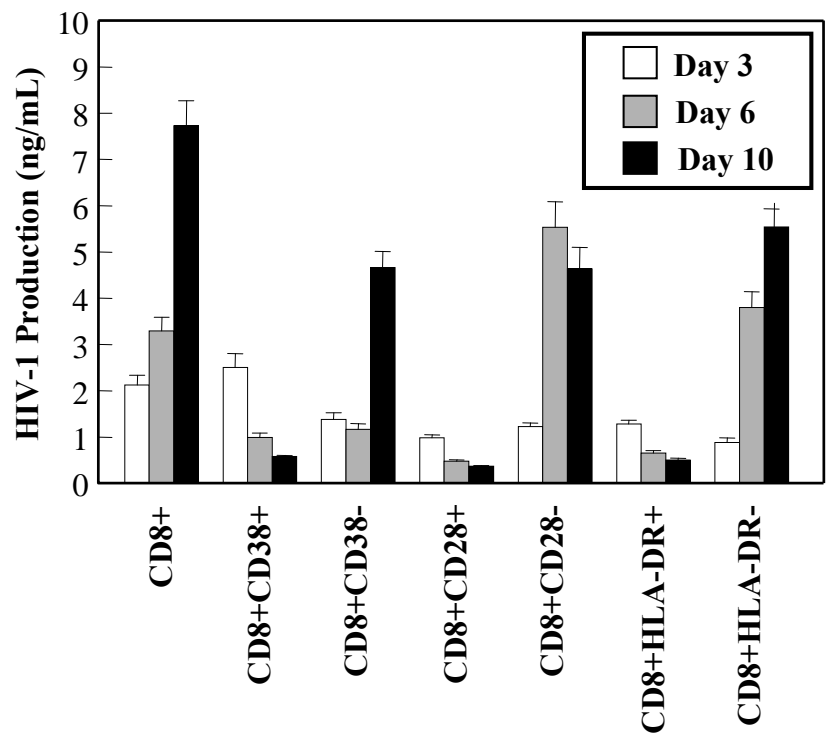

Fig. (5). HIV-1 replication in CD8+ T-cell subsets. CD28, CD38 and HLA-DR positive and negative populations were infected with HIV-1 and cultured. Cell-free supernatant samples were taken postinfection at the indicated time points for measurements of HIV-1 production by an ELISA. Results are the mean and SEM of three independent experiments.

\section{Proliferation of Memory CD8+ T-Cells in Response to HIV-1 Infection}

HIV-1 infection has been reported to affect the frequency and function of circulating CD8+ T-cells, thereby hindering the ability of these cells to eradicate viral infection and maintain T-cell mediated immunity. In order to better define the effect of HIV-1 infection on the function and abilities of the CD8+ T-cell memory subset, CD8+CD45RO+ T-cell proliferation in response to stimulation was measured. As assessed by flow cytometry and shown in Fig. (7A), the majority of the isolated CD8+ T-cells were of the naive subset $(82.5 \%$ CD8+CD45RA+ naive T-cells; $14.5 \%$ CD8+CD45RO+ memory T-cells). The purity of our selected CD8+CD45RO+ memory T-cell population was also assessed. The selected memory T-cell population was devoid of any contaminating CD8+CD45RA+ naïve T-cells (Fig. 7B, right histogram) and was composed of approximately $97 \%$ pure cells of the CD8+CD45RO+ phenotype (Fig. 7B, left histogram).

Prior to mitogen stimulation, the $\mathrm{CD} 8+\mathrm{CD} 45 \mathrm{RO}+$ memory T-cells were infected (or left uninfected) for 7 days. Before measuring proliferation, the activation state of the memory cells was assessed before and after infection (Fig. 7C). Based upon the flow cytometry results, the mean fluorescence of $\mathrm{CD} 28$ expression nearly doubled (uninfected,
A

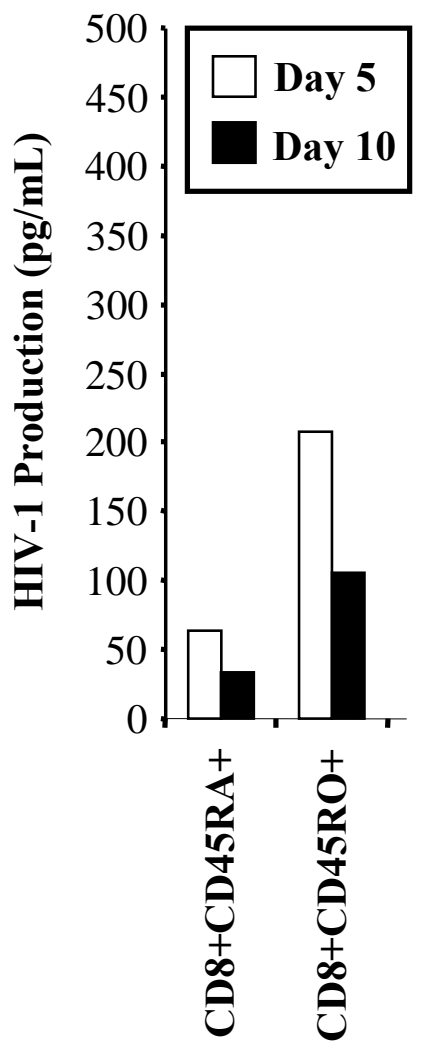

B

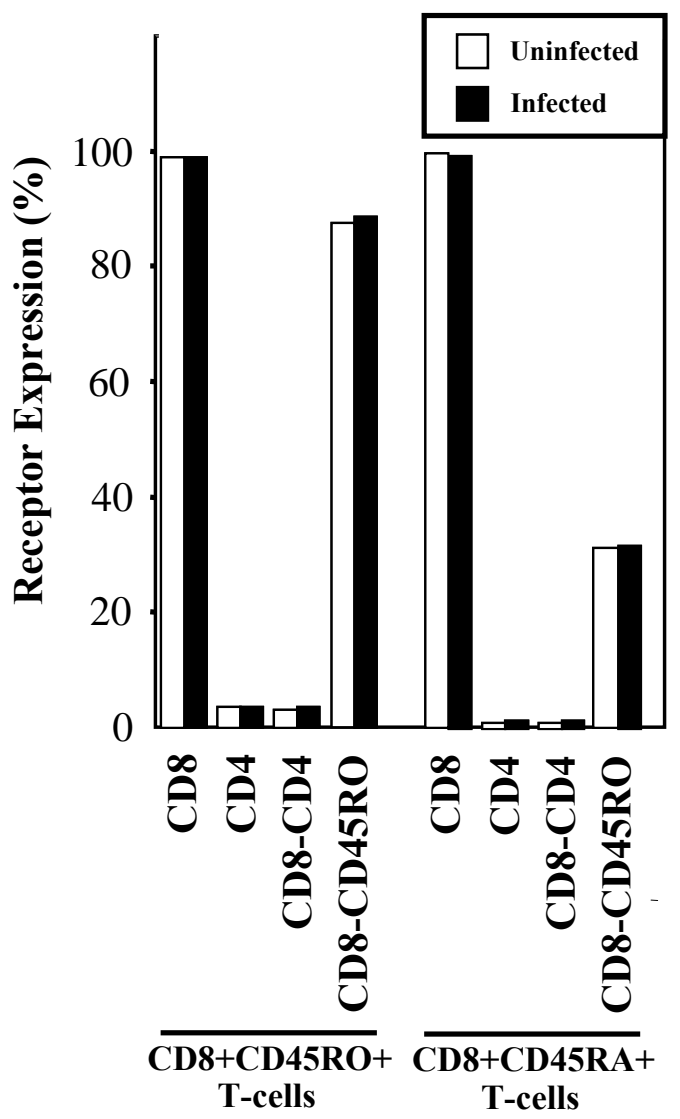

Fig. (6). HIV-1 preferentially replicates in the CD8+CD45RO+ memory T-cells. (A) CD45RO positive and CD45RA positive populations were infected with $300 \mathrm{TCID}_{50} / \mathrm{mL}$ of $\mathrm{HIV}_{\text {IIIB }}$ and cultured. Supernatants were taken at days 5 and 10 post-infection for p24 measurement by ELISA. Results are representative of two independent experiments. (B) Uninfected ( $\square$ ) and infected ( $\mathbf{a})$ memory and naïve T-cells were examined for CD45RO, CD45RA, CD4 and CD8 receptor expression by flow cytometry at day 5 post-infection. 
A

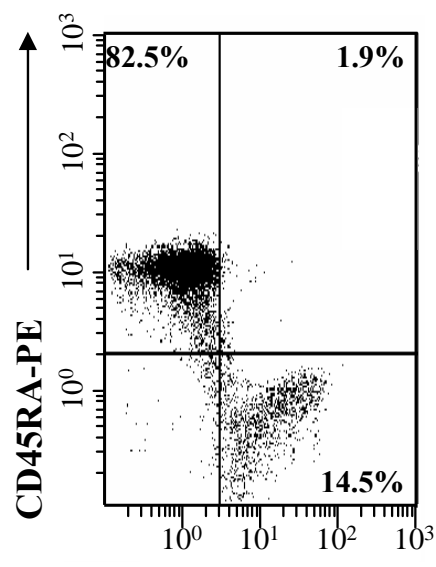

B
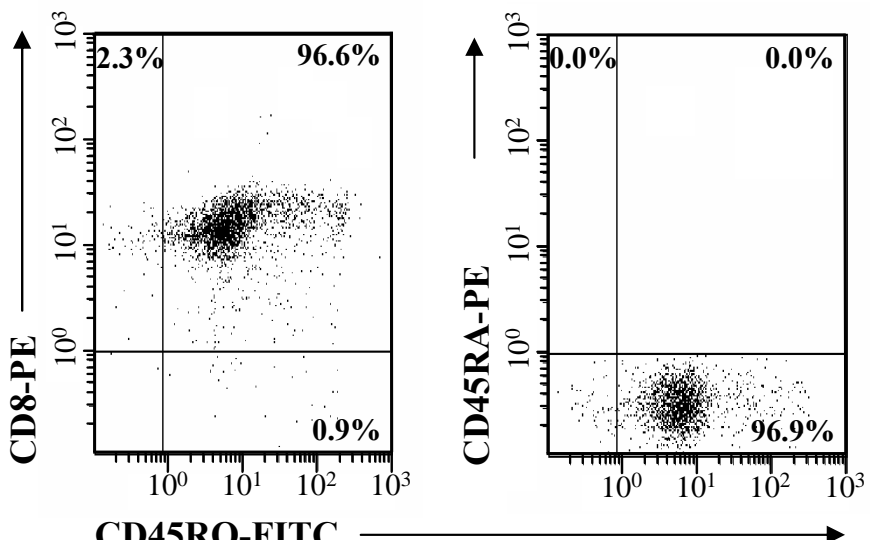

\section{CD45RO-FITC $\longrightarrow$}

C

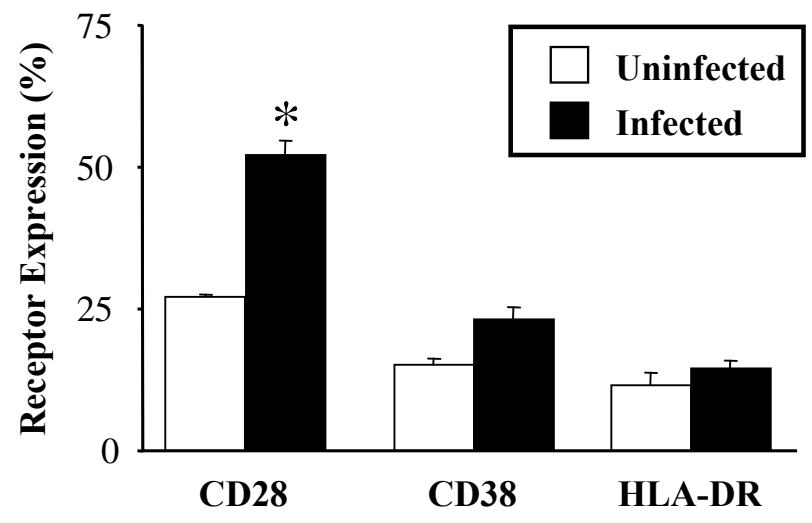

D

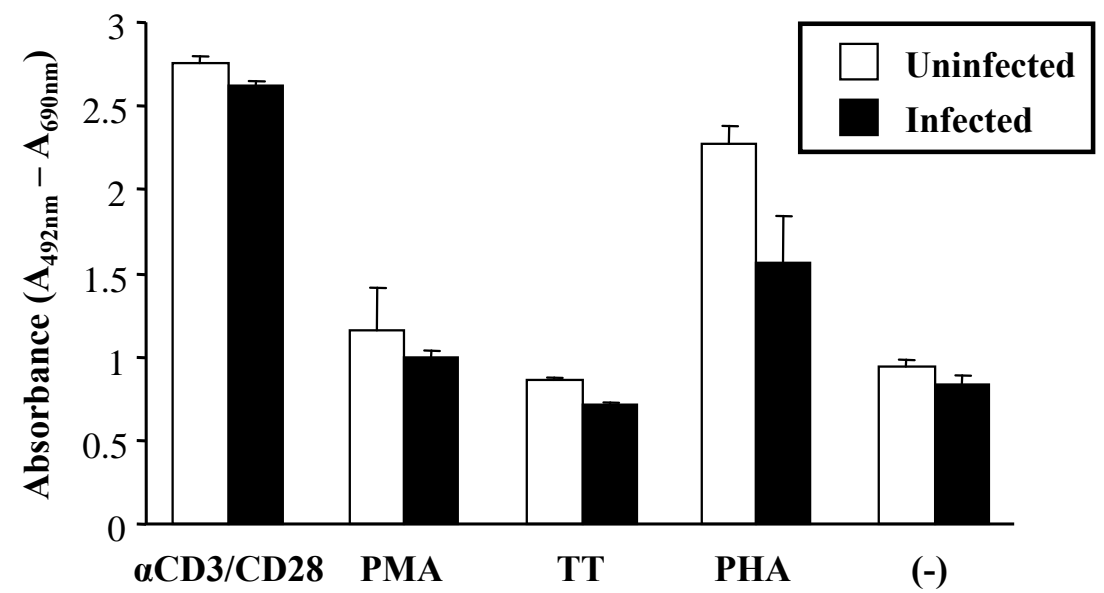

Fig. (7). Proliferative response of HIV-1 infected CD8+CD45RO+ memory T-cells in response to antigenic stimulation. (A) Positively selected CD8+ T-cells were stained with CD45RO-FITC and CD45RA-PE to determine the percentage of memory cells in the isolated CD8+ T-cell population. (B) The purity of the selected CD8+CD45RO+ memory T-cells was assessed by flow cytometry and staining with CD45RO-FITC, CD45RA-PE (right histogram) and CD8-PE (left histogram). Numbers in the quadrants represent the percentage of gated cells in each quadrant. (C) Expression of the activation markers CD28, CD38 and HLA-DR in uninfected ( $\square$ ) and infected ( $\square$ ) CD8+CD45RO+ memory T-cells. Results are the mean percentage and SEM of three independent experiments as measured by flow cytometry. Statistical significance of $p<0.01$ is denoted by an $\left(^{*}\right)$. (D) Lymphocyte proliferative ability of uninfected ( $\square$ ) and infected ( $\left.\mathbf{\square}\right)$ CD8+CD45RO+ memory T-cells as measured by the XTT based colorimetric assay. Memory T-cells were infected (or left uninfected) for 7 days prior to antigen stimulation. Cells were stimulated with $\alpha \mathrm{CD} 3 / \mathrm{CD} 28$, Phytohemagglutinin (PHA), Phorbol Myristate Acetate (PMA), Tetanus Toxoid (TT) or left unstimulated (-). Proliferation was measured at days 2-3 post-antigenic stimulation by labeling with an XTT reagent during the last 18 hours of culture. Results are the mean and SEM of three independent experiments. Data is expressed as the mean absorbance $\left(\mathrm{A}_{492 \mathrm{~nm}}-\mathrm{A}_{690 \mathrm{~nm}}\right)$ and SEM. 
$27.3 \% \pm 0.3$; infected, $52.3 \% \pm 2.4)$ during the course of HIV-1 infection and this was found to be significant ( $\mathrm{p}$-value $=0.0026$ ). There were marginal increases in CD38 and HLA-DR expression in response to infection. To determine the proliferative capacity of the memory subset, cells were stimulated for 2-3 days with various mitogens both in the presence and absence of HIV-1 infection. Based upon the results, it was found that minimal differences in in vitro lymphocyte proliferation between infected and uninfected CD8+CD45RO+ memory T-cells in response to mitogenic stimulation (Fig. 7D) were observed. Overall, HIV-1 infection resulted in a slightly reduced rate of proliferation in the CD8+CD45RO+ memory subset. Mitogenic stimulation with PHA resulted in a greater than 2-fold increase in proliferation in the uninfected memory T-cell population. However, the presence of PHA resulted in an approximately $30 \%$ reduction in the cleavage of XTT in the HIV-1 infected population, indicating a decrease in proliferation. Conversely, $\alpha \mathrm{CD} 3 / \mathrm{CD} 28$ stimulation resulted in a nearly 3 -fold increase in the absorbance values in both the uninfected and infected CD8+CD45RO+ memory T-cell populations.

\section{DISCUSSION}

Despite the accumulating research (and controversy) over the nature of HIV-1 infection of CD8+ T-cells, there is still a lack of information with regard to the effects of viral infection on CD8+ T-cells and their functions. Though previous studies have examined HIV-1 infection of CD8+ T-cells, these studies were limited predominantly to in vivo observations and did not have the availability of sensitive techniques used currently. Many of these studies also focused on the specific and secondary cytolytic abilities of CD8+ T-cells in response to infection and failed to examine or acknowledge the role that CD8+ T-cell subsets such as memory cells play in controlling not only HIV-1 infection, but other viral infections as well. Therefore, we set out to examine the susceptibility of CD8+ T-cells and their subsets to in vitro HIV-1 infection using standard laboratory strains in lieu of serially passaged isolates used in the past, and to examine the effects of infection on CD8+ T-cell function.

We observed that CD8+ T-cells were able to support viral infection and replication. To determine whether or not the infection was productive, we detected HIV-1 presence by RT-PCR analysis and treated the CD8+ T-cells with AZT, a viral replication inhibitor. We found infection to be productive as the presence of the reverse transcriptase inhibitor abrogated HIV-1 production. Of interest was the observation that CD8+ T-cells supported higher levels of replication with T-cell tropic isolates and strains of HIV-1. Similarly, CD4+ T-cells also showed a preferential susceptibility to infection with T-cell tropic strains in vitro. An observation we found throughout our experiments were the differences in viral production and kinetics when CD8+ T-cells were isolated from numerous volunteers. This phenomenon is not restricted solely to CD8+ T-cells as it is also apparent when CD4+ T-cells and macrophages of different individuals are infected in vitro [30]. Our results with T-cell tropic strains and isolates were expected as both CD4+ and CD8+ T-cells express high levels of the chemokine receptor CXCR4 that is predominantly used by the T-cell tropic HIV-1 strains for binding and entry. Specifically, the T-cell tropic laboratory strain HIV $_{\text {IIIB }}$ resulted in the greatest replication and production in the isolated CD8+ T-cell population. Interestingly, the M-tropic laboratory strain, and to a significantly lesser extent the M-tropic clinical isolate, were also able to successfully infect CD8+ T-cells. This may be explained by the presence of moderate CCR5 expression on the surface of the CD8+ Tcells.

Our experimental results have shown that CD8+ T-cells were able to support productive HIV-1 infection. Since the CXCR4 co-receptor was highly expressed on the surface of the CD8+ T-cells and the affinity of gp120 for the CD4 molecule had already been established, we examined the possibility of CD4 up-regulation on the surface of CD8+ Tcells during infection. Our results indicate that CD8+ T-cells supported approximately 10-fold lower levels of in vitro HIV-1 replication than what was routinely observed in CD4+ $\mathrm{T}$-cells, corroborating a report that suggested that CD8+ Tcells were low producers of HIV-1 [31]. A possible explanation for this observation may be due to the low expression of the CD4 molecule on the surface of CD8+ T-cells and subsequent down-regulation of this receptor following infection. In our experiments, increases in CD4 expression by CD8+ Tcells over time in culture did not show a dependence upon infection and was not significantly observed in the in vitro HIV-1 infected CD8+ T-cell population. In addition, the contribution of the CD8+CD4+ T-cells in the total CD8+ T-cell population during HIV-1 infection was less than $2 \%$. Of note was the decrease in the mean fluorescence of the CD8 cellsurface molecule in the infected population. This was most likely due to the cytopathic and anergizing effects of the culturing of CD8+ T-cells in the presence of HIV-1 or the possible down-regulation of this molecule.

Brenchley et al. observed that the number of HIV-1 $1_{g a g}$ DNA copies in $\mathrm{CD} 4{ }^{\mathrm{dim}} \mathrm{CD} 88^{\text {bright }}$ lymphocytes were 5 to 100 fold more than in the CD8+CD4- lymphocytes [32]. However, the majority of cells that were infected with HIV-1 in our in vitro experiments were of the CD8+CD4- phenotype as measured by intracellular HIV-1 $1_{\text {gag }}$ staining. These findings suggest the possibility of an alternate portal of entry that may be used by HIV-1 to enter CD8+CD4- T-cells. The role of the CD8 cell-surface molecule in HIV-1 infection cannot be discounted as recent evidence has shown that CD4independent HIV-1 variants exist in AIDS patients and these viruses preferentially infect $\mathrm{CD} 8+\mathrm{T}$-cells using $\mathrm{CD} 8$ as a receptor $[10,11]$.

Levels of HIV-1 replication were examined in CD8+ Tcells co-expressing CD28, CD38 or HLA-DR. These subsets were selected for study due to their significance in asymptomatic infection and disease progression. From our results, we did not see an increase in susceptibility to HIV-1 infection in the CD28+, CD38+ or HLA-DR+ CD8+ T-cell subsets. It may be argued that the observation that the positively selected populations were unable to support full HIV-1 replication was due to an inherent artifact present in the selection process with conjugated beads. However, when the memory and naïve subsets were examined later on, the positively se- 
lected memory population resulted in the higher level of HIV-1 production, thereby discounting the notion that positive selection hindered susceptibility to infection. Interestingly, these positively selected subsets showed a decrease in viral kinetics over time when compared to the negative fractions. The decrease in replication kinetics may be due to the inability of these cells to support more than a minimal level of replication. Thus, without any suitable cellular target, the virus would eventually be unable to propagate. Of note are the levels of HIV-1 replication in the CD8+CD28- subset. The number of these cells increase early on and throughout the course of infection [33, 34], suggesting that the CD8+CD28- T-cells may be involved in the control of virus replication. If the CD8+CD28- cells are indeed involved in the suppression of HIV-1 replication and, based upon our observations, show an increase in susceptibility to HIV-1 infection, then a key subset of CD8+ T-cells involved in fighting disease may be hampered or eliminated early on in the course of disease.

High levels of replication of HIV-1 were found in the CD8+CD45RO+ memory T-cell subset when compared to the CD8+CD45RA+ naïve T-cell subset. Both the CD8+CD45RO+ and CD8+CD45RA- memory T-cell populations showed significantly higher levels of replication than the CD8+CD45RO- and CD8+CD45RA+ naïve T-cell populations. However, previous research demonstrated that the CD8+CD45RA+ naïve subset was found to have a higher frequency of infection than the memory subset in vivo [35]. In addition, the naivve CD8+ T-cell population has also been shown to be the most susceptible to HIV-1 infection following activation-induced up-regulation of the CD4 cell-surface molecule by antibodies to CD3 and CD28 [18]. While susceptibility to productive infection was observed in the CD8+CD45RA+ naïve T-cell subset in vitro, our results indicate that HIV-1 replicated more efficiently and productively in the memory phenotype of CD8+ T-cells in the absence of activation-induced up-regulation of CD4 cellsurface expression. In CD4+ T-cells, it has been documented that the CD45RO+ memory population serves as the main contributor to the pool of infected T-cells in vivo [36, 37]. The low level of HIV-1 replication in CD8+CD45RA+ naive T-cells may be explained by the observation in CD4+ T-cell studies that infection of naïve CD4+ T-cells by laboratory isolates of HIV-1 results in insufficient T-cell activation that is required for the reverse transcription and integration of the viral genome [38-40]. These same observations may hold true for the infection of memory and naïve CD8+ T-cells in vitro reported here. Work done by Wills et al. may partly explain the high frequency of infection of CD8+CD45RA+ naive $\mathrm{T}$-cells in vivo. The researchers found that the CD8+CD45RA+ T-cells are not comprised solely of naïve Tcells, but also contain a significant proportion of memory $\mathrm{T}$ cells that can change from a CD45RO ${ }^{\text {high }}$ to CD45RA high phenotype in vivo [41]. Thus, during the course of HIV-1 infection in vivo, the memory T-cell subset may play a role as the initial proviral reservoir, but may subsequently revert to the naive T-cell phenotype that has been observed in response to various stimuli.
In order to assess the effects of HIV-1 infection on $\mathrm{CD} 8+\mathrm{CD} 45 \mathrm{RO}+$ memory T-cells, we examined the ability of the infected memory cells to proliferate in response to in vitro HIV-1 infection. It has been postulated that T-cell dysfunction could be attributed to the altered sensitivity of CD8+ (and CD4+) T-cells to various co-stimulatory signals in HIV-1 infected patients. In vivo results have already demonstrated the significant increase in memory T-cell numbers in acute viral infections [42, 43]. These experiments were performed in the absence of any CD4+ T-cell help. A longstanding paradigm in immunology has been the requirement for CD4+ T-cell help in the expansion and maintenance of memory CD8+ T-cells in vivo $[44,45]$. However, evidence has demonstrated that $\mathrm{CD} 4+\mathrm{T}$-cell help was not required for the proliferation and persistence of fully functional antigenspecific memory CD8+ T-cells in the primary immune response [46]. Our findings demonstrated that HIV-1 infection of the CD8+CD45RO+ memory T-cell subset did not impair the proliferative response of these cells to the majority of the mitogens used for stimulation which may be explained by the activation state of these cells. These results may partly be explained by the low levels of HIV infection seen in the CD8+ T-cell population (Fig. 3). If this assumption holds true, the majority of cells would be of the uninfected phenotype in the infected population. Therefore, no differences in proliferation may be due to the larger uninfected population functioning normally. Recently, Holm et al. demonstrated that HIV-1 virions induced CD8+ T-cells to up-regulate CD25 and HLA-DR and preferentially induced apoptosis in the CD8+CD25+HLA-DR+ T-cell subset [47]. Our isolated $\mathrm{CD} 8+\mathrm{CD} 45 \mathrm{RO}+\mathrm{T}$-cells also showed an up-regulation of HLA-DR during in vitro infection. However, our results also demonstrated that HIV-1 infection only minimally decreased proliferation in response to mitogenic stimulation when compared to the uninfected population. The lack of proliferation in the CD8+ memory T-cell population may be partly explained by the observations of Pantaleo et al. [48]. The researchers found that the CD8+HLA-DR+ subset was severely defective in their proliferative response to anti-CD28, anti-CD3, anti-CD2, PHA and PMA. From our in vitro results, HIV-1 infection only resulted in a noticeable decrease in proliferation in the cells stimulated with PHA. Therefore, strong mitogenic stimulation with PHA in the presence of HIV-1 resulted in the decrease in proliferation. This may have led to the triggering of an apoptotic pathway or anergy in the infected CD8+CD45RO+ memory T-cell population by an aberrant form of T-cell activation induced by PHA stimulation. More importantly, naïve cells require stimulation to proliferate and differentiate. Effector cells, on the other hand, are terminally differentiated and thus do not proliferate. Therefore, a lack of proliferation in this subset would be expected. A limitation of our studies is the delineation of the memory and naïve subsets used in the studies. Future studies will examine the phenotype of these populations and assay CD8+ T-cell function by measuring CTL ability and cytokine expression profiles.

In our in vitro system, CD8+CD45RO+ memory T-cells only showed an impairment of their proliferative capacity in response to HIV-1 infection in the presence of PHA stimula- 
tion. The observation that memory T-cells serve as one of the main reservoirs for the virus has profound implications as a high proportion of the expanded CD8+ T-cell population in HIV-1 infected individuals is comprised of CD45RO+ cells [49]. These memory cells have an enhanced susceptibility to cell death [50] and die upon bystander activation [51]. In addition, the $\mathrm{CD} 45 \mathrm{RO}+$ phenotype contributes significantly to the HIV-specific CTL response and these CD45RO+ CTLs are preferentially lost upon disease progression [52]. The effect of infection on CD8+ T-cell CTL function, chemokine and cytokine production, and the susceptibility to apoptosis could have a significant impact upon disease progression and our understanding of HIV-1 pathogenesis. The identification of a novel cellular target and viral reservoir will open up new avenues for treatment of this viral infection in the future.

\section{ACKNOWLEDGEMENTS}

This research was supported by the Ontario HIV Treatment Network (Grant ROGB149) and the Canadian Institutes of Health Research HIV/AIDS Research Program (Grant HOP 48355). NG is the recipient of a CIHR and OGS scholarship and KFTC holds an OHTN salary award.

\section{REFERENCES}

[1] Gulzar N, Copeland KF. CD8+ T-cells: function and response to HIV infection. Curr HIV Res 2004; 2: 23-37.

[2] Walker CM, Moody DJ, Stites DP, Levy JA. CD8+ lymphocytes can control HIV infection in vitro by suppressing virus replication. Science New York, NY. 1986; 234: 1563-6.

[3] Hoffenbach A, Langlade-Demoyen P, Dadaglio G, et al. Unusually high frequencies of HIV-specific cytotoxic T lymphocytes in humans. J Immunol 1989; 142: 452-62.

[4] Klein MR, van Baalen CA, Holwerda AM, et al. Kinetics of Gagspecific cytotoxic $\mathrm{T}$ lymphocyte responses during the clinical course of HIV-1 infection: a longitudinal analysis of rapid progressors and long-term asymptomatics. J Exp Med 1995; 181: 1365-72.

[5] Barker E, Mackewicz CE, Reyes-Teran G, et al. Virological and immunological features of long-term human immunodeficiency virus-infected individuals who have remained asymptomatic compared with those who have progressed to acquired immunodeficiency syndrome. Blood 1998; 92: 3105-14.

[6] Rinaldo C, Huang XL, Fan ZF, et al. High levels of anti-human immunodeficiency virus type 1 (HIV-1) memory cytotoxic Tlymphocyte activity and low viral load are associated with lack of disease in HIV-1-infected long-term nonprogressors. J Virol 1995; 69: 5838-42.

[7] Lewis DE, Tang DS, Adu-Oppong A, Schober W, Rodgers JR. Anergy and apoptosis in CD8+ T cells from HIV-infected persons. J Immunol 1994; 153: 412-20.

[8] Potter SJ, Dwyer DE, Saksena NK. Differential cellular distribution of HIV-1 drug resistance in vivo: evidence for infection of CD8+ T cells during HAART. Virology 2003; 305: 339-52.

[9] Tsubota H, Ringler DJ, Kannagi M, et al. CD8+CD4- lymphocyte lines can harbor the AIDS virus in vitro. J Immunol 1989; 143: 85863.

[10] Saha K, Zhang J, Gupta A, Dave R, Yimen M, Zerhouni B. Isolation of primary HIV-1 that target CD8+ T lymphocytes using CD8 as a receptor. Nat Med 2001; 7: 65-72.

[11] Zerhouni B, Nelson JA, Saha K. Isolation of CD4-independent primary human immunodeficiency virus type 1 isolates that are syncytium inducing and acutely cytopathic for CD8+ lymphocytes. J Virol 2004; 78: 1243-55.

[12] De Maria A, Pantaleo G, Schnittman SM, et al. Infection of CD8+ T lymphocytes with HIV. Requirement for interaction with infected CD4+ cells and induction of infectious virus from chronically infected CD8+ cells. J Immunol 1991; 146: 2220-6.

[13] De Maria A, Colombini S, Schnittman SM, Moretta L. CD8+ cytolytic $\mathrm{T}$ lymphocytes become infected in vitro in the process of killing HIV-1-infected target cells. Eur J Immunol 1994; 24: 531-6.
[14] Sullivan YB, Landay AL, Zack JA, Kitchen SG, Al-Harthi L. Upregulation of CD4 on $\mathrm{CD} 8+\mathrm{T}$ cells: $\mathrm{CD} 4$ dimCD8bright $\mathrm{T}$ cells constitute an activated phenotype of CD8+ T cells. Immunology 2001; 103: 270-80.

[15] Flamand L, Crowley RW, Lusso P, Colombini-Hatch S, Margolis DM, Gallo RC. Activation of CD8+ T lymphocytes through the T cell receptor turns on CD4 gene expression: implications for HIV pathogenesis. Proc Natl Acad Sci USA 1998; 95: 3111-6.

[16] Imlach S, McBreen S, Shirafuji T, Leen C, Bell JE, Simmonds P. Activated peripheral CD8 lymphocytes express CD4 in vivo and are targets for infection by human immunodeficiency virus type 1 . J Virol 2001; 75: 11555-64.

[17] Cochrane A, Imlach S, Leen C, Scott G, Kennedy D, Simmonds P. High levels of human immunodeficiency virus infection of CD8 lymphocytes expressing CD4 in vivo. J Virol 2004; 78: 9862-71.

[18] Kitchen SG, Korin YD, Roth MD, Landay A, Zack JA. Costimulation of naive CD8(+) lymphocytes induces CD4 expression and allows human immunodeficiency virus type 1 infection. J Virol 1998; 72: 9054-60.

[19] Hughes GJ, Willey SJ, Cochrane A, Leen C, Bell JE, Simmonds P. Virus immunocapture provides evidence of CD8 lymphocyte-derived HIV-1 in vivo. AIDS (London, England) 2007; 21: 1507-13.

[20] Weng NP, Levine BL, June CH, Hodes RJ. Human naive and memory T lymphocytes differ in telomeric length and replicative potential. Proc Natl Acad Sci USA 1995; 92: 11091-4.

[21] Tough DF. Deciphering the relationship between central and effector memory CD8+ T cells. Trends Immunol 2003; 24: 404-7.

[22] Grayson JM, Zajac AJ, Altman JD, Ahmed R. Cutting edge: increased expression of Bcl-2 in antigen-specific memory CD8+ T cells. J Immunol 2000; 164: 3950-4.

[23] Becker TC, Wherry EJ, Boone D, et al. Interleukin 15 is required for proliferative renewal of virus-specific memory CD8 T cells. J Exp Med 2002; 195: 1541-8.

[24] Prince HE, Bermudez S, Plaeger-Marshall S. Preparation of CD8bright and CD8dim lymphocyte populations using two positive selection methods in tandem. J Immunol Methods 1993; 165: 139-48.

[25] Kienzle N, Baz A, Kelso A. Profiling the CD8low phenotype, an alternative career choice for $\mathrm{CD} 8 \mathrm{~T}$ cells during primary differentiation. Immunol Cell Biol 2004; 82: 75-83.

[26] Appay V, Almeida JR, Sauce D, Autran B, Papagno L. Accelerated immune senescence and HIV-1 infection. Exp Gerontol 2007; 42: 432-7.

[27] Giorgi JV, Liu Z, Hultin LE, Cumberland WG, Hennessey K, Detels R. Elevated levels of CD38+ CD8+ T cells in HIV infection add to the prognostic value of low CD4+ T cell levels: results of 6 years of follow-up. The Los Angeles Center, Multicenter AIDS Cohort Study. J Acquir Immune Defic Syndr 1993; 6: 904-12.

[28] Ho HN, Hultin LE, Mitsuyasu RT, et al. Circulating HIV-specific CD8+ cytotoxic T cells express CD38 and HLA-DR antigens. J Immunol 1993; 150: 3070-9.

[29] Speiser DE, Migliaccio M, Pittet MJ, et al. Human CD8(+) T cells expressing HLA-DR and CD28 show telomerase activity and are distinct from cytolytic effector T cells. Eur J Immunol 2001; 31: 459-66.

[30] Evans LA, McHugh TM, Stites DP, Levy JA. Differential ability of human immunodeficiency virus isolates to productively infect human cells. J Immunol 1987; 138: 3415-8.

[31] Mercure L, Phaneuf D, Wainberg MA. Detection of unintegrated human immunodeficiency virus type 1 DNA in persistently infected CD8+ cells. J Gen Virol 1993; 74 ( Pt 10): 2077-83.

[32] Brenchley JM, Hill BJ, Ambrozak DR, et al. T-cell subsets that harbor human immunodeficiency virus (HIV) in vivo: implications for HIV pathogenesis. J Virol 2004; 78: 1160-8.

[33] Bouscarat F, Levacher-Clergeot M, Dazza MC, et al. Correlation of CD8 lymphocyte activation with cellular viremia and plasma HIV RNA levels in asymptomatic patients infected by human immunodeficiency virus type 1. AIDS Res. Hum. Retroviruses 1996; 12: 17-24.

[34] Caruso A, Licenziati S, Canaris AD, et al. Contribution of CD4+, CD8+CD28+, and CD8+CD28- T cells to CD3+ lymphocyte homeostasis during the natural course of HIV-1 infection. J Clin Invest 1998; 101: 137-44.

[35] McBreen S, Imlach S, Shirafuji T, et al. Infection of the CD45RA+ (naive) subset of peripheral CD8+ lymphocytes by human immunodeficiency virus type 1 in vivo. J Virol 2001; 75: 4091-102.

[36] Schnittman SM, Lane HC, Greenhouse J, Justement JS, Baseler M, Fauci AS. Preferential infection of CD4+ memory T cells by human immunodeficiency virus type 1: evidence for a role in the se- 
lective T-cell functional defects observed in infected individuals. Proc Natl Acad Sci USA 1990; 87: 6058-62.

[37] Sleasman JW, Aleixo LF, Morton A, Skoda-Smith S, Goodenow MM. CD4+ memory $\mathrm{T}$ cells are the predominant population of HIV-1-infected lymphocytes in neonates and children. AIDS (London, England) 1996; 10: 1477-84.

[38] Chun TW, Chadwick K, Margolick J, Siliciano RF. Differential susceptibility of naive and memory CD4+ T cells to the cytopathic effects of infection with human immunodeficiency virus type 1 strain LAI. J Virol 1997; 71: 4436-44.

[39] Roederer M, Raju PA, Mitra DK, Herzenberg LA. HIV does not replicate in naive CD4 $\mathrm{T}$ cells stimulated with $\mathrm{CD} 3 / \mathrm{CD} 28$. J Clin Invest 1997; 99: 1555-64.

[40] Zack JA, Haislip AM, Krogstad P, Chen IS. Incompletely reversetranscribed human immunodeficiency virus type 1 genomes in quiescent cells can function as intermediates in the retroviral life cycle. J Virol 1992; 66: 1717-25.

[41] Wills MR, Carmichael AJ, Weekes MP, et al. Human virusspecific CD8+ CTL clones revert from CD45ROhigh to CD45RAhigh in vivo. CD45RAhighCD8+ T cells comprise both naive and memory cells. J Immunol 1999; 162: 7080-7.

[42] Jung MC, Schraut W, Santantonio T, et al. Increased frequency of CD8+ CD45R0+ memory T lymphocytes in acute hepatitis B virus infection. J Hepatol 1993; 18: 295-300.

[43] Wherry EJ, Barber DL, Kaech SM, Blattman JN, Ahmed R. Antigen-independent memory CD8 $\mathrm{T}$ cells do not develop during chronic viral infection. Proc Natl Acad Sci USA 2004; 101: 160049 .

[44] Janssen EM, Lemmens EE, Wolfe T, Christen U, von Herrath MG, Schoenberger SP. CD4+ T cells are required for secondary expan- sion and memory in CD8+ T lymphocytes. Nature 2003; 421: 8526.

[45] Salkowitz JR, Sieg SF, Harding CV, Lederman MM. In vitro human memory CD8 $\mathrm{T}$ cell expansion in response to cytomegalovirus requires CD4+ T cell help. J Infect Dis 2004; 189: 971-83.

[46] Marzo AL, Vezys V, Klonowski KD, et al. Fully functional memory CD8 T cells in the absence of CD4 T cells. J Immunol 2004; 173: 969-75.

[47] Holm GH, Gabuzda D. Distinct mechanisms of CD4+ and CD8+ T-cell activation and bystander apoptosis induced by human immunodeficiency virus type 1 virions. J Virol 2005; 79: 6299-311.

[48] Pantaleo G, Koenig S, Baseler M, Lane HC, Fauci AS. Defective clonogenic potential of $\mathrm{CD} 8+\mathrm{T}$ lymphocytes in patients with AIDS. Expansion in vivo of a nonclonogenic CD3+CD8+DR+ CD25- T cell population. J Immunol 1990; 144: 1696-704.

[49] Tedla N, Dwyer J, Truskett P, Taub D, Wakefield D, Lloyd A Phenotypic and functional characterization of lymphocytes derived from normal and HIV-1-infected human lymph nodes. Clin Exp Immunol 1999; 117: 92-9.

[50] Akbar AN, Borthwick N, Salmon M, et al. The significance of low bcl-2 expression by CD45RO T cells in normal individuals and patients with acute viral infections. The role of apoptosis in T cell memory. J Exp Med 1993; 178: 427-38.

[51] McNally JM, Zarozinski CC, Lin MY, Brehm MA, Chen HD, Welsh RM. Attrition of bystander CD8 T cells during virusinduced T-cell and interferon responses. J Virol 2001; 75: 5965-76.

[52] Ogg GS, Kostense S, Klein MR, et al. Longitudinal phenotypic analysis of human immunodeficiency virus type 1 -specific cytotoxic T lymphocytes: correlation with disease progression. J Virol 1999; 73: 9153-60. 